\title{
Pintura mural en el Madrid del siglo XV. La diversidad de un Madrid periférico
}

\author{
Matilde AzCárate LuXÁn, Irene GonZález Hernando, \\ Santiago Manzarbeitia Valle y $\mathrm{M}^{\mathrm{a}}$ Aitana Monge Zapata \\ Departamento de Historia del Arte I (Medieval) \\ Universidad Complutense de Madrid \\ smanzarb@ghis.ucm.es
}

\begin{abstract}
RESUMEN
El presente artículo analiza la diversidad como factor común de los soportes arquitectónicos, estilos pictóricos, técnica pictórica e iconografía de ocho conjuntos murales, que cronológicamente corresponden al siglo XV, ubicados en la periferia del territorio de la actual Comunidad de Madrid.
\end{abstract}

Palabras clave: pintura mural, pintura medieval en Madrid, técnica pictórica mural, pintura del siglo XV, Gótico Lineal, Gótico Internacional, Pintura Hispano-flamenca, Arte Románico en Madrid.

\begin{abstract}
This paper analyzes diversity as a common factor in the architecture, style, technique and iconography of eight programs of mural paintings created in the 15th century in the periphery of what is now the territory of Madrid.
\end{abstract}

Keywords: mural painting, medieval mural painting in Madrid, pictorical technique, XVth century painting, Linear Gothic painting, International Style, Hispano-flemish painting, Romanesque Art in Madrid.

\section{Los soportes arquitectónicos de los murales madrileños del siglo XV}

Varios templos dispersos por el actual territorio de la Comunidad de Madrid custodian en sus paredes restos de pintura mural medieval de diversa cronología, estilo y calidad. Analizar de manera conjunta los que soportan murales realizados en el siglo XV, presenta no pocas dificultades, ya que nos encontramos ante conjuntos templarios de variable entidad y con un devenir histórico que en ocasiones ha jugado en su contra, desfigurando hasta lo irreconocible, su aspecto original. Los templos aquí analizados se localizan en tres amplias áreas geográficas diferenciadas -Sierra Norte, Zona Este y Zona Suroeste- con un notable carácter hídrico por estar asociadas a las cuencas de los principales ríos que atraviesan la región: Alta del Manzanares y Jarama, Henares y Tajuña, y Alberche, respectivamente.

Estas iglesias (Camarma de Esteruelas, Navalafuente, Torremocha de Jarama, Villa del Prado, Griñón, Valdelaguna y Colmenar Viejo) son fruto de su tiempo ya que se materializaron en terrenos del centro peninsular arrancados -lenta y costosamente- de las manos musulmanas, siendo repoblados a finales del siglo XI por cristianos que perseguían ventajas fiscales, propiedades con las que progresar y -de 


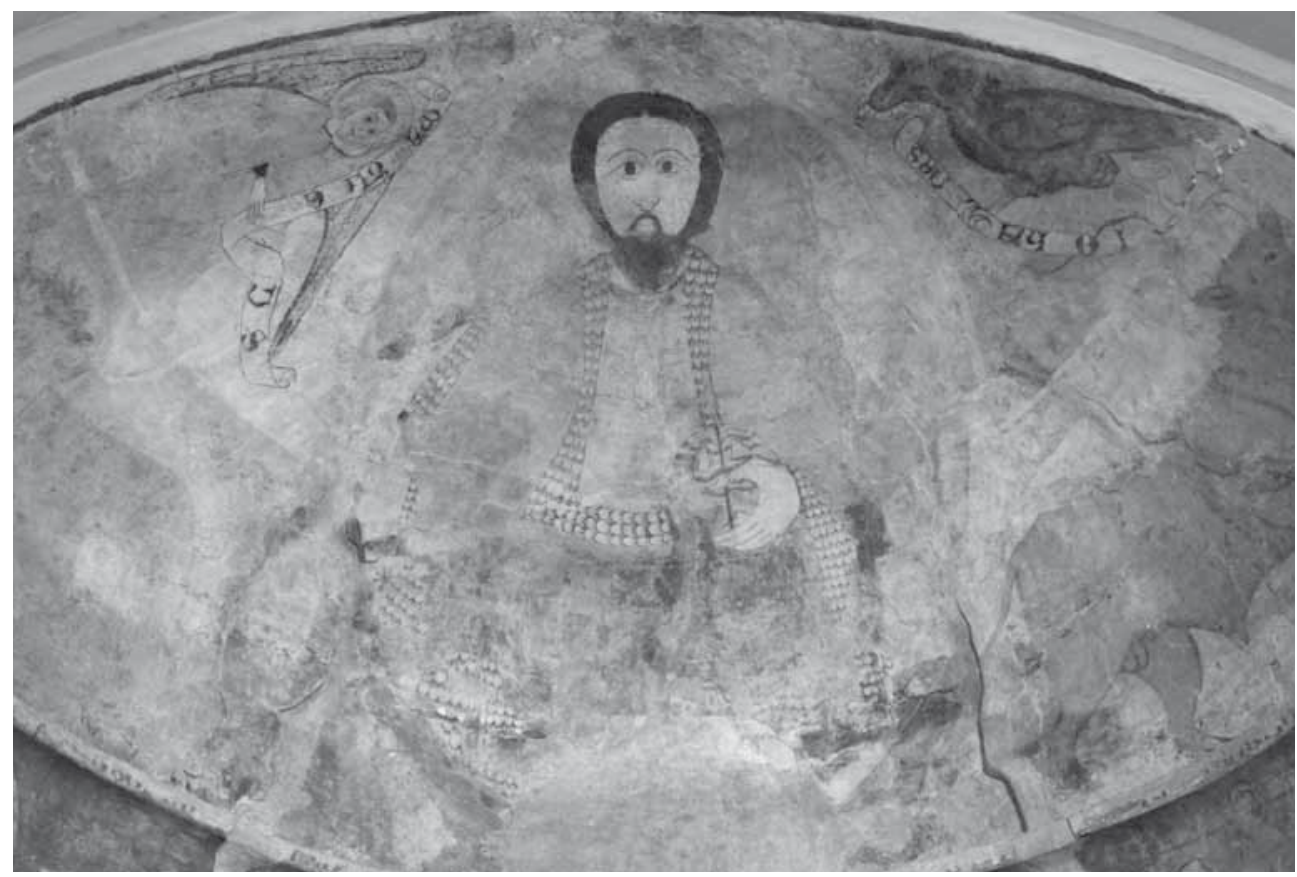

Camarma de Esteruelas, casco absidal, h. 1385-1400.

paso- la salvación de sus almas. Aunque los territorios de las nuevas poblaciones, donde se levantaron los templos que nos ocupan, carecieron antaño de unidad territorial por encontrarse en zonas de repoblación cristiana bajo la órbita de las grandes capitales de su entorno (Segovia, Ávila y Toledo), en la actualidad quedan inscritos bajo la jurisdicción de la capital del país ${ }^{1}$.

Un comentario conjunto requiere mencionar brevemente las principales características constructivas de cada templo, a fin de precisar su marco cronológico, repasar su transformación a lo largo del tiempo y valorar su estado de conservación actual.

De la primitiva construcción "mudéjar" del siglo XIII del templo parroquial de San Pedro Apóstol de Camarma² sólo se conserva la cabecera, formada por un

1 Vid. J. NUÑO GONZÁLEZ (coord.), "La Enciclopedia del románico en Madrid. Algunas consideraciones sobre el planteamiento de este trabajo", Enciclopedia del Románico. Madrid, Aguilar de Campoo, 2008, pp. 17-18.

2 Para profundizar en la historia de Camarma de Esteruelas y en las características de su iglesia parroquial véase: M.C. ABAD CASTRO, "Iglesia de San Pedo de Camarma de Esteruelas (Madrid). Arciprestazgo de Madrid", Arquitectura mudéjar religiosa en el arzobispado de Toledo, vol. II, Toledo, 1991, pp. 44-49; M.J. ARNÁIZ et alii, Libro-guía del visitante de la iglesia de San Pedro Apóstol: Camarma de Esteruelas, Alcalá de Henares, 1994; J.M. AZCÁRATE RISTORI (dir.), Inventario artístico de la Provincia de Madrid, Valencia, 1975, p. 92; I. HERNÁNDEZ GARCÍA DE LA BARRERA, "Camarma de Esteruelas", Enciclopedia del Románico.Madrid, Aguilar de Campoo, 2008, pp. 309-312; M. MAYORAL MORAGA, Camarma de 
bello ábside articulado al exterior mediante un triple orden de arquerías de medio punto dobladas y ciegas montadas sobre un zócalo de mampostería. Igual estructura presenta el presbiterio, que permaneció oculto hasta la década de los noventa del pasado siglo, momento en que se demolieron sendas capillas anejas a la mayor. La articulación muraria interna se resuelve mediante arquería ciega de arcos apuntados. Las sucesivas intervenciones modificaron significativamente el aspecto de la iglesia, que pudo ser de nave única y lucir una torre de la cual sólo algunos indicios nos demuestran su existencia bajo la del siglo XVI.

La iglesia parroquial de San Bartolomé de Navalafuente ${ }^{3}$ tiene su origen en el siglo $\mathrm{XV}$, aunque sólo se conservan de esta cronología la capilla mayor y la capilla lateral del norte, cubierta con bóveda de crucería y terceletes. Al exterior se combinan la mampostería vista y la enjalbegada. En cronología moderna se construyó una modesta espadaña al oeste, y se le adosaron en el costado meridional un pórtico y una sacristía que da sensación de falso crucero al disponerse frente a la capilla del siglo XV.

La iglesia parroquial de San Pedro de Torremocha de Jarama ${ }^{4}$ debió comenzarse a construir en los años finales del siglo XIII o en los primeros del XIV, aunque de esa primitiva ermita medieval sólo se conservan escasos restos en la cabecera -semicircular con presbiterio- y en la torre. Estas dos partes responden a la sintaxis constructiva propia de un románico inercial y retardatario de carácter popular. El antiguo cuerpo eclesial pudo resolverse mediante cuatro tramos cubiertos con bóveda de cañón, que en el siglo XV experimentaría una ampliación hacia poniente y se cubriría con una estructura de madera atirantada. En época moderna, y gracias a la implicación directa del cardenal Cisneros, se añadió otra nueva nave al norte

Esteruelas: de la aldea medieval a la villa moderna, Alcalá de Henares, 1995; B. PAVÓN MALDONADO, Alcalá de Henares medieval: arte islámico y mudéjar, Alcalá de Henares, 1982, pp. 117-118; A. PÉREZ PÉREZ, Camarma. Datos de pequeña historia, Valencia, 1982; y F.C. SAINZ DE ROBLES, Crónica y guía de la provincia de Madrid (sin Madrid), Madrid, 1966, p. 460.

3 Para profundizar en la historia de Navalafuente y en las características de su iglesia parroquial véase: J.M. AZCÁRATE RISTORI, op. cit., 1975, p. 202; A. BLANCO MANZANARES, Navalafuente, un pueblo, una historia, Leganés, 1995; F. MENÉNDEZ PIDAL DE NAVASCUÉS, "Navalafuente", Boletín de la Real Academia de la Historia, CXCII (1995), p. 522; R. MORENO BLANCO, "Navalafuente", Enciclopedia del Románico. Madrid, Aguilar de Campoo, 2008, pp. 431-432; F.C. SAINZ DE ROBLES, op. cit., 1966, p. 509.

4 Para profundizar en la historia de Torremocha y en las características de su iglesia parroquial véase: J.M. AZCÁRATE RISTORI, op. cit., 1975, pp. 282-283; M. CID e I. DE LAS HERAS, Torremocha de Jarama. Apuntes para una historia, Madrid, 1996; Arquitecturas restauradas, una década de intervención en el Patrimonio Histórico de la Comunidad de Madrid. 1986-1995, Madrid, 1995, esp. "Restauración de la iglesia parroquial de San Pedro de Torremocha del Jarama", pp. 230-236; R. MORENO BLANCO, "Torremocha del Jarama", Enciclopedia del románico. Madrid, Aguilar de Campoo, 2008, pp. 497-500; R. GARCÍA VALCÁRCEL, El Valle del Jarama, Documadrid, Madrid, 2001, pp. 127-135; J. GUTIÉRREZ MARCOS (dir.), Iglesia parroquial de San Pedro. Torremocha de Jarama, Colección "Madrid Restaura en Comunidad", Madrid, 1993; M. HERNÁNDEZ AGUADO, Las rutas del agua: Patones, Torrelaguna y Torremocha de Jarama, Colección "Descubre tus cañadas”, 5, Madrid, 1998, pp. 31-35; A. DE LA MORENA BARTOLOMÉ, "Pintura mural medieval en la Comunidad de Madrid", Anales de Historia del Arte, 4 (1994a), pp. 633-644; F.C. SAINZ DE ROBLES, op. cit., 1966, p. 612; y A.J. SANZ HERNÁN, La Villa de Torremocha de Jarama. Anales de un Concejo y crónica de un Ayuntamiento, Madrid, 1990. 


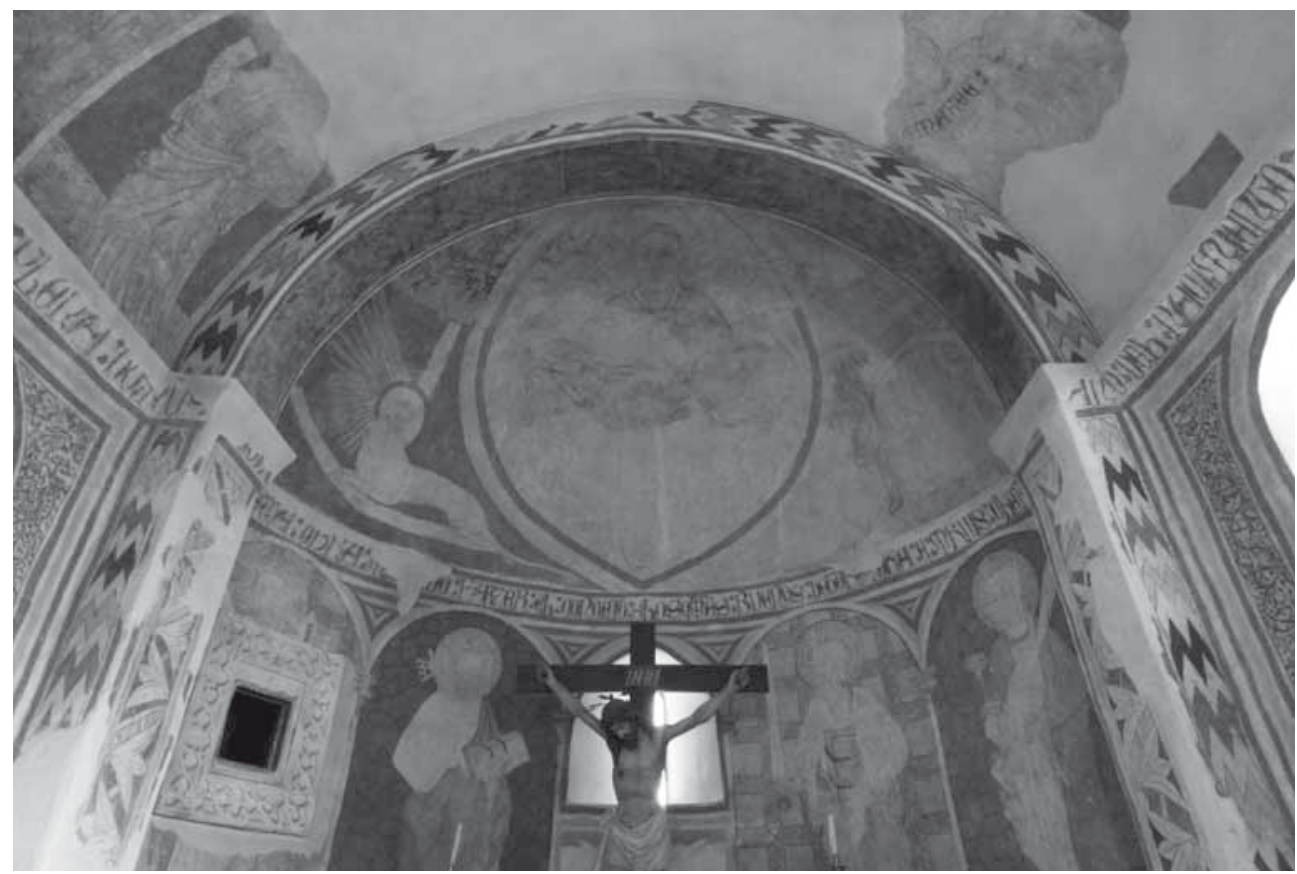

Torremocha de Jarama, ábside, h. 1450.

y se habilitó un pórtico renaciente que abrazaba el templo por sus lados occidental y meridional, de estilo próximo a la escuela de Gil de Hontañón, ostentando las armas del promotor episcopal. Tras sucesivas intervenciones, la de 1865 consiguió desfigurar el aspecto de la iglesia al demoler los muros sur y oeste para ampliar el espacio interior. Los trabajos de restauración acometidos en el siglo XX intentaron devolver al templo su estructura original.

La iglesia parroquial de Santiago Apóstol de Villa del Prado ${ }^{5}$ fue iniciada en el siglo XV por la zona de la cabecera, interrumpiéndose las obras en la nave que se concluyó con otro proyecto, aunque debieron culminarse los trabajos del conjunto a comienzos del siglo siguiente. Su nave, complementada con una serie de capillas habilitadas entre los contrafuertes, se remata hacia el este con un rotundo ábside poligonal cubierto con bóveda nervada.

5 Para profundizar en la historia de Villa del Prado y en las características de su iglesia parroquial véase: J. AGUILERA et alii, Ángeles y dragones: la restauración de la Iglesia de Santiago Apóstol de Villa del Prado, Aranjuez, 2003; J.M. AZCÁRATE RISTORI, op. cit., 1975, pp. 310-311; J.M. LEONET ZABALA, Villa del Prado en el siglo XXI. Historia. Tradiciones, arte, economía, costumbres y fiestas, Madrid, 2003; F.C. SAINZ DE ROBLES, op. cit., 1966, pp. 279-281; V. TORRES SOLANA, "Iglesia parroquial de Santiago Apóstol", Arquitectura y desarrollo urbano. Comunidad de Madrid. Zona oeste, t. VIII, Madrid, 1999, pp. 397-400. 
La parroquia de Nuestra Señora de la Asunción de Griñón ${ }^{6}$ fue levantada en el mismo solar que desde el siglo XV ocupó la primitiva ermita, aprovechando algunas piezas que coinciden con las más antiguas del templo moderno, parte de los muros de la nave y el cuerpo bajo de la torre. En la primera mitad del siglo XVI se recreció la nave única y se construyó la cabecera poligonal actual, completándose con cuatro capillas septentrionales en el XVIII. En la fachada de los pies se conserva un vano geminado con arquillos de herradura y alfiz, que hace eje con la sobria puerta de acceso, recordando el aspecto que tendría la primera construcción mudéjar.

La parroquia dedicada a Nuestra Señora de la Asunción de Valdelaguna ${ }^{7}$ es un edificio de planta basilical, de nave única, cabecera semicircular y falso crucero al que sigue un añadido meridional a modo de nave de dos tramos. La parte más antigua del templo es la cabecera, de estructura románica con presbiterio y cuenca absidal en semicírculo que cubre con una irregular bóveda de cañón apuntado que se continúa con otra de horno carente de imposta para la zona de la capilla.

Es incuestionable que, debido a la situación meridional y fronteriza de los territorios de la actual Comunidad de Madrid, las iniciativas constructivas generadas durante el Medievo sean retardatarias e inerciales, por producirse una superposición estilística propiciada por la coincidencia y la sucesión de distintas corrientes artísticas procedentes del norte y del sur ${ }^{8}$. Madrid, por su condición de frontera cristiana, y por la escasa entidad histórica previa, estuvo dentro de las áreas de influencia de los territorios circundantes, viéndose influida por las obras románicas del reino de Castilla, el impulso constructivo de los nuevos territorios conquistados, y las técnicas musulmanas tan arraigadas en la zona9.

La localización preferente de los restos pictóricos medievales en estas iglesias madrileñas es la cabecera o sus inmediaciones, algo lógico teniendo en cuenta que las zonas más antiguas conservadas son esas precisamente. En los ejemplos más tardíos se aprecia cómo los restos murales se ubican también en otras zonas secundarias dentro de la iglesia tales como las capillas, pero durante los siglos medieva-

6 Para profundizar en la historia de Griñón y en las características de su iglesia parroquial véase: J.M. AZCÁRATE RISTORI, op. cit., 1975, pp. 310-311; P. MARTÍN-SERRANO GARCÍA, "Iglesia parroquial de Nuestra Señora de la Asunción. Griñón”, Arquitectura y desarrollo urbano. Comunidad de Madrid. Zona sur, t. XI, Madrid, 2004, pp. 615-618; F. C. SAINZ DE ROBLES, op. cit., 1966, p. 489.

7 Para profundizar en la historia de Valdelaguna y en las características de su iglesia parroquial véase: J.M. AZCÁRATE RISTORI, op. cit., 1975, pp. 287-288; R. MORENO BLANCO, "Valdelaguna", Enciclopedia del Románico. Madrid, Aguilar de Campoo, 2008, pp. 505-508.

8 Cfr. A.E. MOMPLET MIGUEZ, "El románico en Madrid”, Enciclopedia del Románico. Madrid, Aguilar de Campoo, 2008, pp. 52-53.

9 "En Madrid el románico autóctono que se conserva es sobre todo marginal, geográficamente hablando, ubicados hacia los flancos norte, este y oeste, próximo a Segovia, Guadalajara y Ávila, provincias todas muy ricas en ese tipo de arquitectura y con las que las inmediatas comarcas madrileñas comparten dinámica histórica": J. NUÑO GONZÁLEZ (coord.), op. cit., 2008, p. 17. 


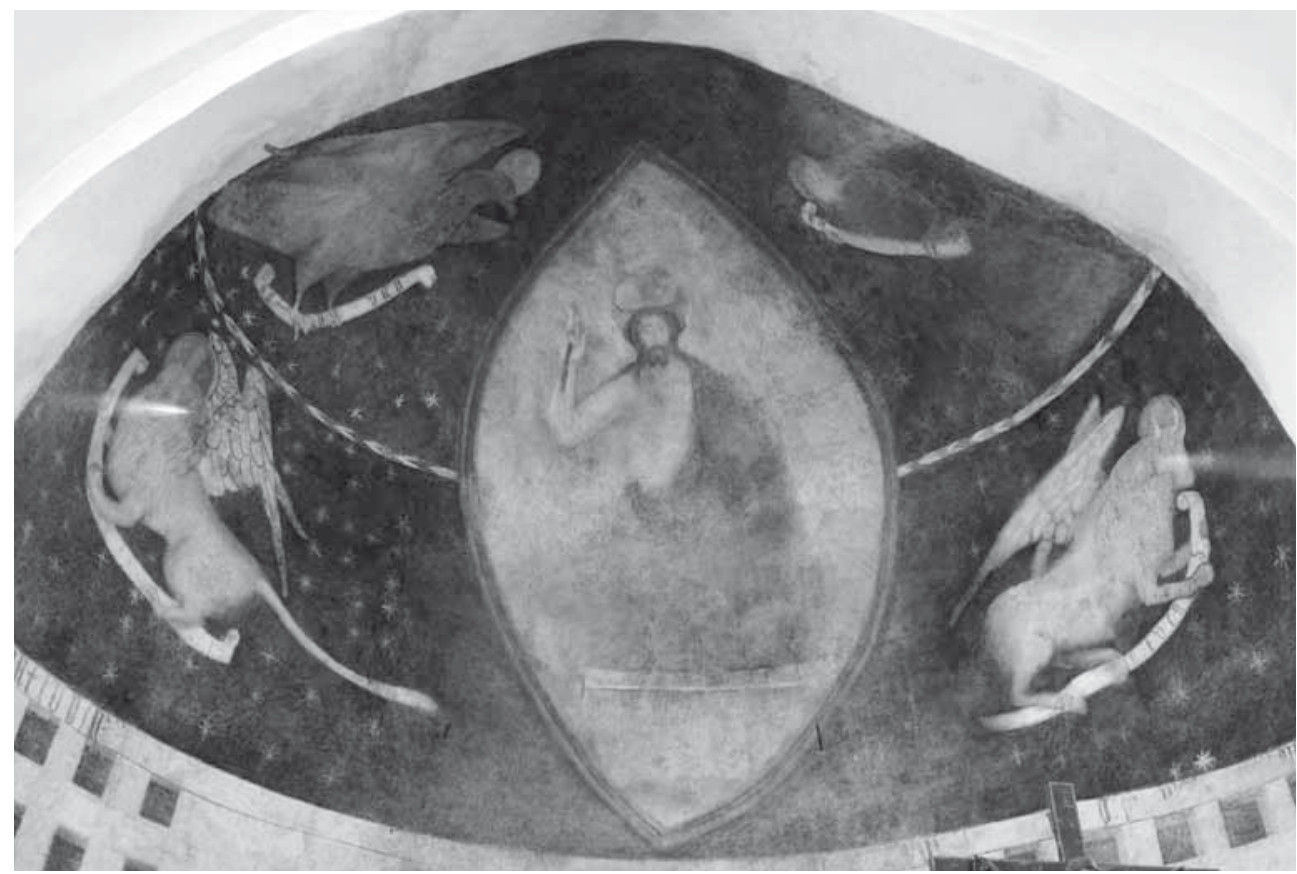

Valdelaguna, casco absidal, h. 1500.

les lo normal es perseguir la dignificación y el enriquecimiento de la cabecera por ser el espacio celebrativo y litúrgico más importante del templo.

La abundancia de iglesias madrileñas que se construyeron en ladrillo (y también en ladrillo y mampostería ${ }^{10}$ a partir de la primera mitad del siglo XIII, de las cuales en el mejor de los casos se conservan algunas partes de los muros perimétricos y de la torre además de la cabecera, nos hablan de una actividad edilicia con un claro regusto autóctono y con unas soluciones determinadas por la propia naturaleza del material empleado ${ }^{11}$. Además, se ha de tener en cuenta que la pobreza de esas zonas rurales, por lo general deprimidas o con escaso dinamismo socioeconómico, ha favorecido un continuismo constructivo y acomodaticio que progresivamente ha ido adaptando las viejas fábricas a las nuevas necesidades litúrgicas con el menor

${ }^{10}$ La influencia constructiva toledana debe verse en la frecuente combinación del ladrillo y el mampuesto. Cfr. A.E. MOMPLET MIGUEZ, op. cit., 2008, p. 55.

11 "La diferente naturaleza en todos los aspectos (peso, tamaño, resistencia, forma de cohesionarse, etc.) resulta determinante en el resultado formal de lo construido. Ello afectará a la definición de elementos tan esenciales de un edificio como sus muros, soportes, cubiertas y vanos. Variarán, entre otras cosas, su forma, sus dimensiones, su color y sus propios elementos constructivos-decorativos. Todo ello condiciona de manera importante la caracterización estilística de los edificios": A.E. MOMPLET MIGUEZ, op. cit. 2008 , p. 54. 
coste posible, encontrándose sólo de forma excepcional iglesias de nueva planta en que se prescinde por completo de cualquier vestigio previo ${ }^{12}$.

Los dos ejemplos más notables del llamado mudéjar madrileño son San Pedro de Camarma de Esteruelas y San Martín de Valdilecha ${ }^{13}$, edificios ambos que conservan bellísimas cabeceras de ábsides semicirculares y presbiterios rectos previos, con soluciones decorativas al exterior y/o al interior, de gran efectismo plástico y notable sofisticación técnica a partir de la superposición de arquerías ciegas de ladrillo y remates en cornisa de canecillos escalonados, que precisamente fueron los lugares escogidos para la incorporación de pinturas murales. En el caso de Camarma, su cronología es ligeramente posterior a la construcción románica de Valdilecha, a cuya decoración nos remitiremos como referencia, pero que no incluimos en este artículo por corresponder al estilo tardorrománico de finales del siglo XIII. Testimonios de románico mudéjar más modesto es el de la iglesia de San Bartolomé de Navalafuente, donde las pinturas del ábside se han perdido casi totalmente.

Otros templos como los de San Pedro de Torremocha de Jarama y Nuestra Señora de la Asunción de Valdelaguna enmascararon bajo una generosa capa de cal o un revoco pictórico, la pobreza de materiales de estas partes, aunque en ambos casos, las modestas cuencas absidales se ornaron con programas iconográficos todavía en parte conservados.

Por último, y como lógica evolución constructiva, tenemos los ejemplos de Nuestra Señora de la Asunción de Griñón, Santiago de Villa del Prado y la parroquial de la Asunción de Colmenar Viejo, correspondientes al gótico, con cabeceras poligonales o muros que al interior conservan testimonios pictóricos tardomedievales.

Ya sean edificios románicos, mudéjares, góticos, románicos mudéjares, góticos mudéjares, de románico en ladrillo, de repoblación..., los templos medievales mencionados, aun no siendo siempre los mejores testimonios, sí son los únicos que conservamos de arquitectura medieval madrileña con muros pintados que -como testimonios de excepción- nos hablan de la espiritualidad del momento, del sentir de sus gentes, del arte al servicio de la religión en unos territorios ganados por la fe y repoblados en su nombre.

12 "Hay zonas en las que una endémica pérdida de población no hizo necesaria la ampliación de los viejos templos, y la secular falta de recursos tampoco hizo posible que se pudieran renovar para adaptarlos a los nuevos gustos estéticos": J. NUÑO GONZÁLEZ (coord.), op. cit., p. 17.

13 "Existen otros aspectos que se vienen considerando básicos a la hora de diferenciar y definir un edificio como mudéjar. Se trata de la asociación de aspectos constructivos y decorativos mediante el tan característico uso dual del ladrillo. Asimismo, resulta definitiva la presencia de otros elementos procedentes de la arquitectura hispanomusulmana como puedan ser los arcos de herradura, túmidos o lobulados, así como el protagonismo de las armaduras de madera en detrimento de las bóvedas, unidos a las técnicas y al sistema de trabajo": A.E. MOMPLET MIGUEZ, op. cit., 2008, p. 54. 


\section{La diversidad de estilos en la pintura mural del siglo XV en Madrid}

De las doce iglesias de la Comunidad de Madrid que conservan conjuntos o restos de pintura mural medieval, más de la mitad quedan enmarcados en un dilatado siglo XV. La secuencia cronológica se inicia aproximadamente hacia 1385-1400 con la decoración absidal de Camarma de Esteruelas realizada en un estilo lineal final. Por el otro extremo la cronología supera, hasta aproximadamente quince años, el límite de 1500 en varias pinturas de concepción y espíritu todavía plenamente góticos, aunque el adjetivo hispanoflamenco no defina más que parcialmente los conjuntos de Villa del Prado y Valdelaguna, los restos de las escenas de Griñón y algo más adecuadamente, la Misa Gregoriana tras el retablo de Colmenar Viejo. Sobre todo en Villa del Prado hay elementos, de una calidad y madurez estilística, que se corresponden ya con el primer Renacimiento. Entre los extremos mencionados, los débiles restos pictóricos de Navalafuente (primer cuarto del s. XIV) y el singular conjunto de estilo internacional de Torremocha (h. 1450), ocupan los años centrales del siglo.

Los estilos mencionados se corresponden con la tradicional y reconocida secuencia estilística gótica que se sucede en España del siglo XIII al siglo XV, con la salvedad de la ausencia de muestras del estilo italogótico. Hecho que va aparejado a la ausencia de restos murales en todo el territorio de la actual Comunidad, durante casi la totalidad del siglo XIV.

En casi todos los casos, la filiación estilística de los ejemplos madrileños se puede establecer con focos artísticos vecinos como Toledo, Segovia, Ávila o Guadalajara ${ }^{14}$, no sólo en relación con la propia técnica mural, sino también con la pintura sobre tabla. Y es que como no podía ser de otra forma, y también ha quedado visto en el estudio arquitectónico previo, Madrid, por su condición fronteriza primero, de repoblación después, es artísticamente periférica durante la Edad Media y lo seguirá siendo hasta convertirse en Corte filipina en 1561. Aún teniendo en cuenta las referencias documentales de la existencia de restos pictóricos en la Villa, nada hace suponer la existencia de un núcleo pictórico de cierta entidad en ella ${ }^{15}$ a finales del siglo XV.

El Pantocrátor de Camarma, iconográficamente, es cierto, es herencia del consabido modelo románico, si bien su estilo y ciertos elementos simbólicos corresponden al gótico. La dilatada pervivencia de esta composición se debió sin duda al hecho de ser la fórmula que mejor se adaptaba a la superficie cóncava de los áb-

14 Idéntica dependencia o vinculación a la que puede establecerse en lo referente a las fábricas arquitectónicas que las soportan.

15 Para más detalles consultar las fuentes citadas por A. DE LA MORENA BARTOLOMÉ, op. cit., 1994a, p. 634. De los casos citados, en ninguno se habla de calidad (salvo de forma negativa sobre el San Cristóbal del pórtico de la iglesia de Santa María) y de las dos imágenes murales trasladadas -La Flor de Lis de esa misma iglesia y La Piedad de Los Jerónimos- decir que se conservaron por devoción. 
sides románicos y mudéjares ${ }^{16}$. Tras un estudio comparativo con representaciones similares anteriores del foco tardorrománico toledano (cuyo ejemplo más cercano en el espacio es Valdilecha, Madrid), con varias contemporáneas del estilo gótico lineal castellano y leonés, así como con el posterior, muy perdido e intervenido, de Torremocha (adscrito al estilo internacional de mediados del s. XV), creemos que la obra debe inscribirse dentro del último estilo gótico lineal y que fue realizada con posterioridad a 1385 .

La comparación con Valdilecha nos hace ver lo que las separa técnica y estilísticamente. Los murales de Valdilecha fueron realizados todavía en una técnica propia del románico, base de buen fresco, sobre mortero de cal y arena, y retoques en seco, lo que sorprende debido a la avanzada fecha de ejecución posterior a 1250. Los análisis no evidencian restos de proteínas, con lo que el acabado en seco se supone fue al agua de cal y no un temple graso ${ }^{17}$. En Camarma, llama la atención que las pinturas fueran realizadas sobre un simple enlucido de yeso de $2 \mathrm{~cm}$ de espesor y con temple, lo que en buena parte justifica su mal estado y vulnerabilidad. Respecto al estilo, Valdilecha, aunque Sureda, Bango y de la Morena coinciden en una cronología aproximada, para Sureda son tardorrománicas, para Bango, se infiere que románicas, aunque subraya su carácter lineal y caligráfico, mientras que de la Morena las incluye ya dentro del estilo lineal ${ }^{18}$. Queda abierta la cuestión estilística del conjunto de Valdilecha (estilo 1200 -tardorrománico- estilo lineal) que de momento aquí no vamos a abordar. Lo que sí nos parece evidente es que el estilo del casco de Camarma ya no es tan caligráfico en los detalles; los cuerpos de los animales son más pesados y redondeados, y también es mayor el recargamiento ornamental, sobre todo visible en el Pantocrátor ${ }^{19}$.

De la Morena ${ }^{20}$ ha apreciado muy acertadamente la cercanía de los rasgos faciales del Pantocrátor de Camarma (cejas finas y arqueadas, ojos rasgados y nariz trebolada) con los del San Cristóbal del retablo del Prado ( $\left.{ }^{\circ} 3150\right)$, del siglo

16 Esta observación fue realizada por Gutiérrez Baños en su tesis sobre el estilo lineal en Castilla y León: F. GUTIÉRREZ BAÑOS, Aportación al estudio de la pintura de estilo gótico lineal en Castilla y León, 2 vols., Madrid, 2005.

17 Para los datos estilísticos y técnicos de Valdilecha remitimos a la monografía de I. BANGO et alii, Estudio histórico de la iglesia de San Martín de Valdilecha, Madrid, 1981.

18 A. DE LA MORENA BARTOLOMÉ, op. cit., 1994a, p. 635 y nota 14.

19 Hemos creído necesaria esta notable diferenciación estilística y técnica de Camarma con Valdilecha, que nos lleva a una diferencia cronológica de más de un siglo, para dejar constancia de ella. Las referencias bibliográficas más recientes siguen sin precisar al respecto y se reducen al consabido argumento de la pervivencia iconográfica de la figura del Pantocrátor del siglo XIII hasta el XV en los murales madrileños. Cfr.: R. CARDERO LOSADA, "La iglesia parroquial de Santorcaz. Un ejemplo de arquitectura mudéjar madrileña", Anales de Historia del Arte, 8 (1998), pp. 105 y 114, así como las fichas "San Mamés", "Santorcaz", "Torremocha", "Valdelaguna" y "Valdilecha", firmadas por R. MORENO BLANCO o la de "Camarma de Esteruelas", firmada por I. GARCÍA DE LA BARRERA en la Enciclopedia del Románico. Madrid, Aguilar de Campoo, 2008.

20 A. DE LA MORENA BARTOLOMÉ, op. cit., 1994 a, p. 636. 
XIV y probablemente de procedencia riojana. Por nuestra parte encontramos además un paralelismo con dos murales abulenses, los de Santa María la Mayor de Arévalo y los de la iglesia de Madrigal de las Altas Torres ${ }^{21}$. En la composición de Arévalo, la mejor conservada, la figura del Pantocrátor tiene una disposición análoga al de Camarma, con la salvedad de que la mano izquierda que sostiene el orbe, está levantada mientras en Camarma reposa en el regazo. Aunque en Camarma no se conservan las líneas de contorno e intornos, las borduras del manto de armiño nos dan la idea volumétrica de la figura y ayudan a definirla. Estas borduras coinciden con lo que en el de Arenas son bordura y forro, si bien aquí no se ha conservado tal elemento decorativo o no existió dándose todavía más importancia a la cursividad del trazo de los pliegues. Gutiérrez Baños califica el estilo de Arévalo como un estilo lineal final, donde todavía se aprecia la cursividad del trazo y la intensidad de color característico del estilo lineal pero que va cediendo terreno a lo decorativo, exactamente lo que parece ocurrir en Camarma, donde además el gusto por las formas y líneas más redondeadas supondrían un paso más en la lenta disolución del estilo. Si Arenas se fecha en su inscripción hacia 1384, el casco de Camarma debe ser ligeramente posterior, es decir de muy finales del siglo XIV.

Otros detalles de Camarma, como los nimbos gallonados del Tetramorfos (presentes también en Torremocha a mediados del XV), la perspectiva abatida del pie del Pantocrátor, la simplificación del orbe que porta, el menor despliegue de las alas del Tetramorfos, el escote cerrado, o la menor angulosidad de las inscripciones, pueden llevarnos incluso a los primeros años del siglo XV. Podemos afirmar por tanto que a principios del siglo $\mathrm{XV}$, el viejo estilo lineal seguía vigente en su última fase, aunque en descomposición, como lo demuestran también los precarios y esquemáticos restos de Navalafuente ${ }^{22}$. Descomposición que parece acompañada de una pérdida de calidad técnica.

Tras un paréntesis de décadas, durante el cual las novedades italianas llegadas a Toledo con Starnina resultan estériles para Madrid (aunque fructifican en tierras de Cuenca y Valladolid), el conjunto de estilo internacional de Torremocha nos pone a mediados de siglo en contacto con la pujante escuela aragonesa a través de Guadalajara. Este conjunto, ha sido pormenorizadamente estudiado por este mismo equipo, por lo que remitimos a las conclusiones ya publicadas ${ }^{23}$. Torremocha, estilísticamente es una isla en el medio del panorama pictórico madrileño del siglo XV;

${ }^{21}$ F. GUTIÉRREZ BAÑOS, op. cit., 2005, vol. II, p. 43 y ss., p. 97 y ss.

22 De la Morena data estos fragmentos (que identifica con la figura de una santa y dos donantes) en las primeras décadas del siglo XV (A. DE LA MORENA BARTOLOMÉ, op. cit., 1994a, pp. 637-638), mientras que una referencia a la restauración realizada por la Empresa Prado Doce S.A. en 1993, para la Comunidad de Madrid, las data ya en la segunda mitad e identifica a la figura central con una Virgen entronizada con Niño.

${ }^{23}$ M. AZCÁRATE LUXÁN, et alii, "Las pinturas murales de la iglesia de San Pedro en Torremocha del Jarama", Anales de Historia del Arte, volumen extraordinario 1 (2010), pp. 151-170. 


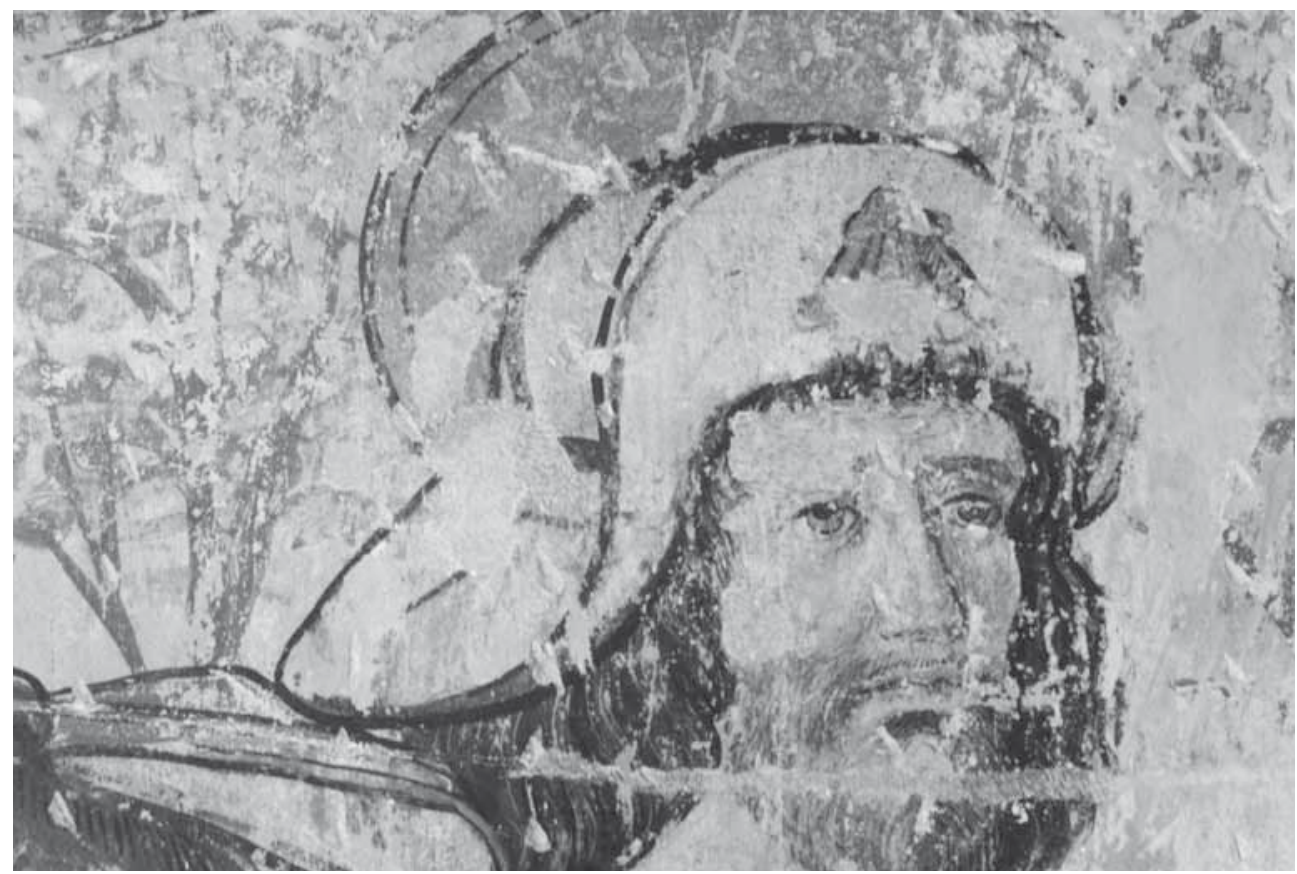

Griñón, Santiago Matamoros, h. 1500.

su vinculación con la escuela aragonesa y la mencionada ausencia de la influencia toledana, nos muestra de nuevo el carácter periférico de los murales madrileños.

A finales de siglo, tenemos en cambio cuatro interesantes muestras. Las pinturas de Valdelaguna fueron realizadas sobre una preparación de mortero de yeso extraordinariamente fino, sobre una capa de cola orgánica, que actuaría de aislante, y con colores en un aglutinante de aceite de linaza, aplicados en una capa muy fina y única. Estamos por tanto ante el uso del óleo sobre el muro, una experimentación que rompe con la técnica tradicional y al que se debe el aspecto pulverulento de la pintura y su aspecto desdibujado. Por esa razón no es fácil una definición estilística, que genéricamente podemos calificar de hispanoflamenca analizando algunos detalles y elementos como el volumen, la composición y la epigrafía de los tres animales del Tetramorfos, que no han sido tan alterados como el hombre de San Mateo y el Pantocrátor, repintados con un temple de huevo y cola ${ }^{24}$. El casco absidal aparece dividido por una fina cenefa con un motivo en espiga y un colorido

24 Los datos técnicos proceden de la memoria de restauración firmada en 2003 por el restaurador Guillermo Fernández García, en el que se incluye un análisis químico de Enrique Parra Crego, un estudio histórico-artístico del arqueólogo Manuel Flores Díez y abundante documentación fotográfica del proceso. Este informe se inicia fechando los murales, para nosotros erróneamente, como de finales del XIII o de la primera mitad del XIV. 


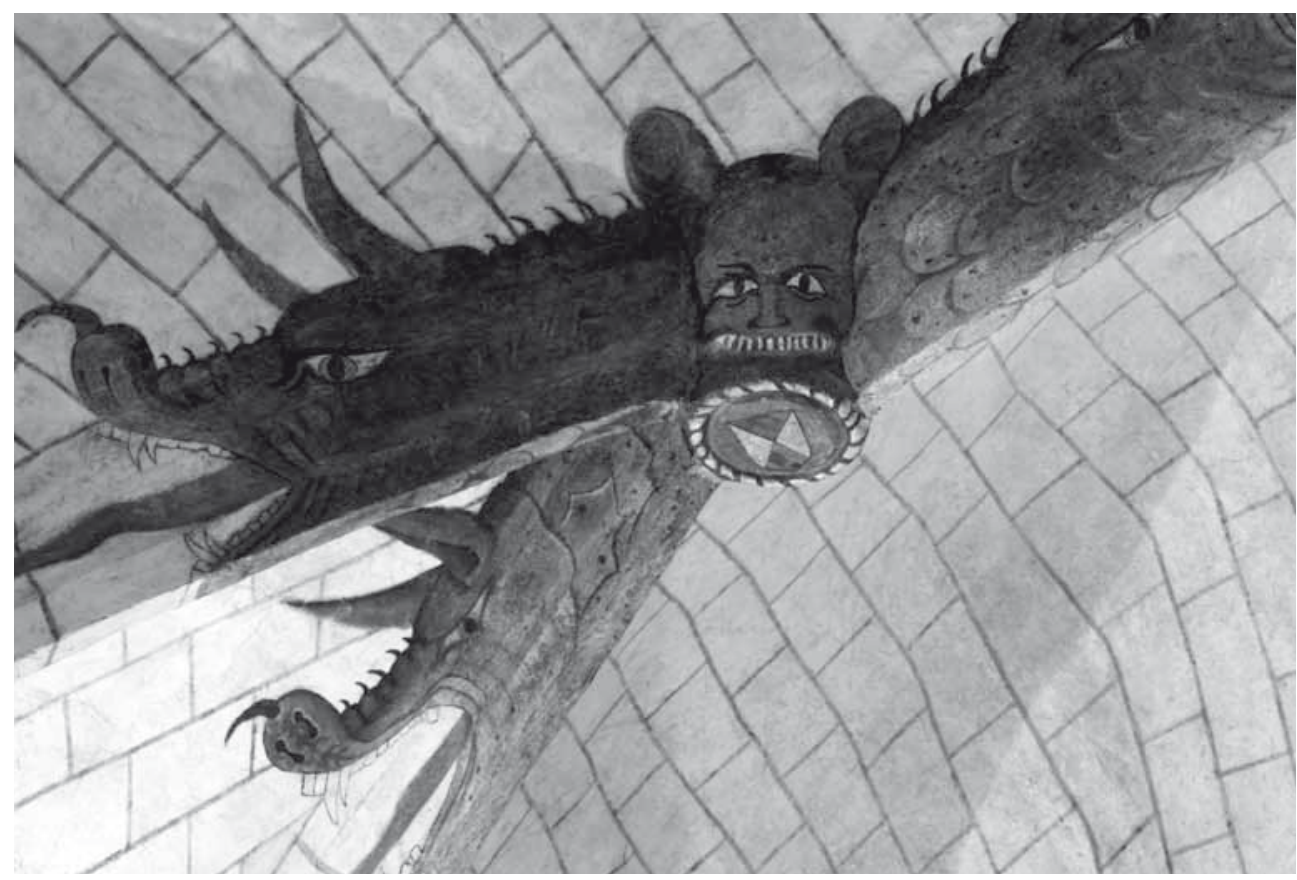

Villa del Prado, dragones y máscara, h. 1500.

similar a uno de los vistos en Torremocha, pero en nada más encontramos afinidad estilística entre ambos. El otro elemento relevante en Valdelaguna es el muro de casetones e inscripción en caracteres góticos que ocupa todo el medio cilindro, a modo de trampantojo, de difícil interpretación, pero que muestra un efecto ilusionista de perspectiva realizado en grisalla, todo lo cual nos lleva a una fecha tardía del siglo XV.

De los fragmentos conservados en Griñón, la figura de Santiago Matamoros, y especialmente su cabeza es realmente de una excelente calidad. En ella puede apreciarse la técnica pictórica de tratteggio para las carnaciones, al modo italiano del temple magro del Renacimiento con el que parece estar realizada. Su composición, como la de la Virgen de la Misericordia, peor conservada, y el fondo adamascado de esta última, parecen soluciones vinculadas o tomadas de la pintura sobre tabla de finales del siglo XV. Las pinturas fueron realizadas sobre un grueso enlucido, bajo el que subyace otro coloreado que podría corresponder a unas pinturas anteriores ${ }^{25}$.

${ }^{25}$ Cfr. El Informe General de la restauración, realizada por Ana Santamaría y Lucila Rodríguez de Austria en 1998, en la Consejería de Educación y Cultura de la Comunidad de Madrid, que financió dicha intervención. Durante la misma se restauró en la sacristía adyacente un friso epigráfico de leyendas con alabanzas a la Virgen y a Santa Ana. 
La intensa actividad pictórica y mejora técnica del ejemplo anterior volvemos a encontrarla por los mismos años en la iglesia de Villa del Prado, en la que debemos distinguir tres grupos de pinturas realizadas entre finales del XV y aproximadamente 1509. Especial singularidad tienen las de los muros de la llamada Capilla del Santo Cristo, muros en ángulo del tramo que precede a la capilla bautismal. Los murales fingen una galería de arcos sobre un muro, en cuyo alfeizar se colocan jarrones con plantas florales y un jardín de árboles frutales entre los que vuelan los pájaros. La arquitectura fingida y el punto de vista muestran un conocimiento de los planteamientos teóricos de la perspectiva italiana ${ }^{26}$. La similitud con las pinturas realizadas hacia 1509 por Juan de Borgoña en la Antesala de la Sala Capitular de la Catedral de Toledo, llevan a considerarlas de su mano o de uno de sus discípulos (Antonio Coomontes o Pedro Delgado), más teniendo en cuenta que el propio Borgoña trabajó para esta iglesia ${ }^{27}$. Estas pinturas fueron realizadas sobre una decoración pintada de sillares que constituyen un "muro ideal"; posiblemente -hay evidencias de ello- se extenderían por todo el muro del sotocoro, fingiendo una especie de atrio ajardinado a los pies del templo. Pero la técnica utilizada -al parecer óleo sobre enfoscado de cal- parece la culpable de no haberse conservado más que en el ángulo de la capilla del Santo Cristo, precisamente por haber sido cubiertas de un nuevo enlucido y la representación de Jerusalén en el siglo XVII. La exquisitez y delicado colorido de estos murales son una muestra temprana del estilo del Primer Renacimiento en Madrid.

En fechas similares debieron realizarse los dragones que aprovechan el volumen de los nervios de las bóvedas de crucería. Motivo de origen gótico y muy recurrente, como se mencionará en el apartado de iconografía, debe destacarse su colorido contrastado, su efectismo y el elemento fantástico propio de este momento de transición de finales de la Edad Media y del que es buen ejemplo alguna máscara intercalada entre estos motivos. Estas máscaras, así como las fauces draconianas recuerdan las tarascas de las procesiones del Corpus, de las que hay memoria desde el siglo XVI. El último grupo de pinturas se sitúa en el muro testero de la cabecera y entre los nervios de la bóveda que cubre el espacio de la misma, quedando ocultas tras el retablo.

En la plementería de la bóveda es visible la figura casi completa del león de San $\operatorname{Marcos}^{28}$, con una excelente volumetría y rico matiz de tonalidades, así como los desnudos de Adán y Eva que muestran similar efecto pictórico, además de una interesante ambientación paisajística que contrasta con el convencionalismo de las estrellas doradas que salpican todo el celaje. Sobre el muro recto se aprecia

${ }^{26}$ Cfr. O. MARÍN CRUZADO, "Las pinturas de la sala capitular de la catedral de Toledo: aportación al estudio de la concepción del espacio”, Archivo Español de Arte, 292 (2000), pp. 319-321.

27 Cfr. J. AGUILERA et alii, op. cit., 2003, pp. 98-101. Restos de una figura pintada en grisalla sobre fondo azulado, situada en el lado de la Epístola, cerca de la cabecera, nos parece que no está lejana a su estilo.

${ }_{28}$ El resto de las figuras del Tetramorfos y del Pantocrátor permanecen ocultas tras las pinturas del XVII. 
la figura de Santiago Matamoros sobre un caballo blanco persiguiendo a un jinete musulmán, sobre un fondo de paisaje muy deteriorado, aunque fragmentariamente, se aprecia una calidad similar a las pinturas que acabamos de mencionar, además de un interés suntuoso en los detalles dorados que adornan el arnés del caballo o el nimbo y la armadura del Apóstol. Un estilo en resumen, que como el de Juan de Borgoña, muestra el conocimiento de las novedades italianas, pero que mantiene el gusto decorativo del oro en los adornos para dar suntuosidad, algo propio de la tradición hispanoflamenca. Todas estas figuras debieron realizarse en un mismo momento y por una misma mano.

Por último, a estas mismas fechas, debe pertenecer el retablito de tracería estucada que hoy permanece oculto tras el retablo mayor de la parroquial de Colmenar Viejo, posible complemento del sepulcro de Benito López, cura de Collado Mediano, fallecido en 1500, trasladado al levantarse el actual retablo en 1579 según de la Morena ${ }^{29}$. La Misa de San Gregorio, que es el tema principal, aunque hay restos de un calvario en el ático, es similar en composición y estilo a la representación del tema en tabla en la escuela castellana de finales del XV y primeros años del XVI, dentro de la influencia flamenca. No obstante, la relación apuntada con el círculo de Pedro Berruguete, no nos parece acertada, pues su estilo carece de la monumentalidad, la perspectiva y en resumen de una personalidad que queda patente incluso entre sus seguidores.

\section{La diversidad iconográfica de los murales madrileños del siglo XV}

Del análisis individual de los programas iconográficos pueden extraerse varias conclusiones. La primera de ellas es que, en líneas generales, hay una continuidad con la iconografía románica. Es por ello que en el cascarón de los ábsides se le suele recordar al fiel la proximidad del fin de los tiempos y la promesa de la Segunda Venida de Cristo, cuestión que se materializa en la figura del Pantocrátor flanqueado por el Tetramorfos, tal como son descritos en los libros de Ezequiel y Daniel así como en el Apocalipsis ${ }^{30}$. Así aparece en las iglesias de Camarma, Torremocha, Villa del Prado y Valdelaguna, aunque con ligeras variaciones de unas a otras; y también en las de Valdilecha y Santorcaz, que aún siendo anteriores al XV, son su más claro precedente. Donde se halla una mayor divergencia es en la representación de la divinidad, que oscila desde la majestad, serenidad e inmutabilidad de conjuntos como Camarma y Torremocha, hasta la aparición de la humanidad de Cristo que resucitado y saliendo del sepulcro exhibe sus llagas, caso del repintado

${ }^{29}$ Su descubrimiento y primer estudio fue publicado por de la A. DE LA MORENA BARTOLOMÉ, "Pinturas murales en el Presbiterio: La Misa de San Gregorio", Cuadernos de Estudios. Colmenar Viejo, 6 (1994b), pp. 117-124.

30 En relación a las fuentes del Pantócrator véase Apocalipsis 4, 2-1; respecto al Tetramorfos o los cuatro vivientes Apocalipsis 4, 7-9, Ezequiel 1, 5-10 y Daniel 7, 1-7. 


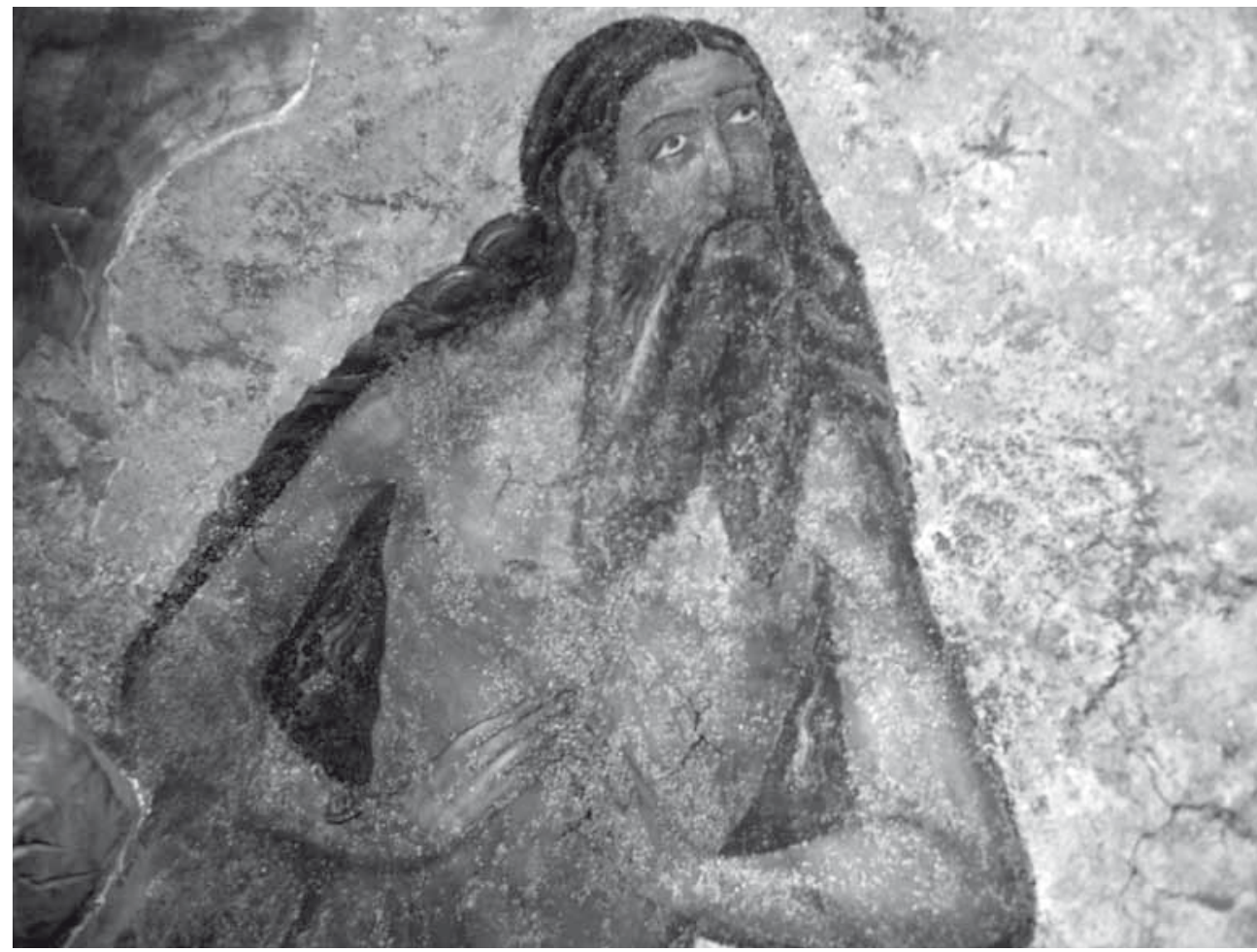

Villa del Prado, Adán, h. 1500.

ejemplo de Valdelaguna, pudiéndole dar entonces el calificativo de Varón de Dolores, más propio de la religiosidad bajomedieval que del sentir románico.

En Villa del Prado, los restos son tan parciales que es inapreciable la forma original de la divinidad ${ }^{31}$. De modo que hay que recurrir a Camarma y Torremocha, conjuntos más completos en cuanto a su conservación, para comprender cómo sería la imagen del Pantócrator entronizado. En Torremocha parece seguir la descripción del anciano de los muchos días que hace Daniel 7, 9, mientras que en Camarma adopta la fisonomía de Cristo siríaco, impasible en su expresión, dándose por tanto la identificación y confusión entre Padre e Hijo que es propia del Pantócrator. La peculiaridad de Torremocha estriba en que flanquean la cabeza del Todopoderoso el sol y la luna sobre un fondo de estrellas, símbolos de la idea de eternidad, pues estamos ante "el que es, el que era y el que ha de venir, el

31 En Villa del Prado, como en Santorcaz apenas pueden verse algunos trazos de la figura del Pantocrátor. En Valdilecha sólo se conserva la parte inferior del trono y la mandorla, pero podría complementarse con la figura del Pantocrátor del Cristo de la Luz de Toledo que porta el Libro de la Vida. 


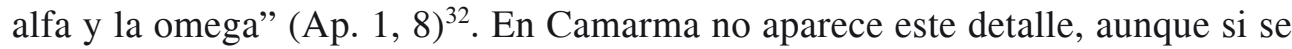
incluye la esfera en la mano izquierda de Dios que, como en Torremocha, recuerda el poder y dominio de éste sobre todas las cosas.

Respecto al Tetramorfos, su estado de conservación es bastante parcial en Torremocha y Villa del Prado ${ }^{33}$, de modo que es en Camarma y Valdelaguna donde hallamos los ejemplos más completos. No obstante, en todos los casos se reconoce fácilmente, ya que cada viviente o evangelista es representado por su símbolo (San Marcos por el león, San Lucas por el toro, San Juan por el águila y San Mateo por el ángel), identificación que se refuerza a veces por las filacterias que contienen sus nombres (véanse por ej. Valdelaguna y Camarma).

La ubicación de los "vivientes" es relativamente uniforme: San Mateo y San Juan ocupan los ángulos superiores, San Marcos y San Lucas los inferiores. Sin embargo, mientras que San Marcos aparece sistemáticamente en el ángulo izquierdo y San Lucas en el derecho, la situación de San Mateo y San Juan puede variar. Lo más frecuente es encontrar a San Mateo en el ángulo izquierdo y San Juan en el derecho, tal como ocurre en Camarma. Sin embargo, esta posición se puede invertir, pasando San Juan a ocupar un lugar más preeminente, a la diestra de Dios, es decir el ángulo izquierdo según la visión del espectador, tal como ocurre en Valdelaguna y Torremocha. Esto es habitual en la Península Ibérica ya que San Juan Evangelista, como hermano de Santiago, cobró gran importancia en el entorno del camino de Santiago, y por esto mismo adoptó esta posición privilegiada.

Una segunda nota común a todos los conjuntos estudiados es que la visión apocalíptica del Pantócrator y el Tetramorfos suele ser completada con representaciones de Adán y Eva, o de la Pasión de Cristo, o con apóstoles y santos, que refuerzan el mensaje transmitido a los fieles y evidencian la evolución devocional y litúrgica de los usos religiosos desde el siglo XII al XVI.

Contamos con ejemplos de la caída de Adán y Eva en Camarma y Villa del Prado, escenas que, al contraponerse al Pantócrator, aluden al inicio y fin de los tiempos. En Camarma la expulsión del hombre del paraíso se sitúa en el interior del arco triunfa ${ }^{34}$. En Villa del Prado la representación de Adán y Eva, situada en el

32 Para más detalles sobre el programa iconográfico de Torremocha, puede verse M. AZCÁRATE LUXÁN et alii, op. cit., 2010, pp. 156-160.

${ }^{33}$ En Torremocha se conserva el león alado, una decoración geométrica a modo de cintas, unos débiles trazos que parecen corresponder a un atril de escritorio, y parte del águila que acompaña a San Juan. En Villa del Prado sólo se observa el león descabezado de San Marcos.

${ }^{34}$ Se trata de una excelente síntesis del pasaje del Génesis 3, 1-24. El pintor ha prescindido de la representación de Eva, a quien se suele colocar como inductora al pecado. Una posibilidad es que Eva estuviese representada enfrente de Adán, ocupando parte de los paramentos que hoy han perdido sus restos murales. La otra, es que se hubiese optado por representar exclusivamente a Adán como símbolo del género humano, entroncando con la descripción del Génesis, 1, 27 en que se afirma que Dios creó "al hombre a imagen suya, a imagen de Dios lo creó, y los creó macho y hembra". Con la figura de Adán se resume por tanto el género humano, hombres y mujeres a un mismo tiempo. 
propio cascarón del ábside, más que incidir en el pecado original (Génesis 3, 1-8), muestra el arrepentimiento tras este hecho, lo que nos acerca a la devotio moder$n a^{35}$. Se potencia así una relación más directa del fiel hacia Dios, haciendo hincapié en la importancia de la meditación, la reflexión individual y la penitencia. Adán y Eva van cubiertos con hojas de higuera, lo que indica que ya han probado del árbol de la ciencia, pero con las manos juntas, en posición de oración ${ }^{36}$. Eva entrelaza sus manos junto a la serpiente, como si ésta también participase de su arrepentimiento, además de para recordar que la primera en ser tentada fue ella.

En Camarma y Villa del Prado la vinculación iconográfica entre Génesis y Apocalipsis remite a la tradición románica y entronca con otros conjuntos castellanos tales como la iglesia de la Vera Cruz de Maderuelo. Cercanas resultan también las pinturas de la iglesia de los Santos Justo y Pastor en Segovia o las de la iglesia de San Román de Toledo.

Respecto a la Pasión de Cristo, las escenas de mayor antigüedad se han conservado en la parte inferior del ábside de Torremocha, datado a inicios del s. $\mathrm{XV}^{37}$. Se trata de una Crucifixión ${ }^{38}$, lo que refuerza la vinculación entre la Primera Venida de Cristo al mundo para llevar a cabo la redención de los hombres, y la Segunda Venida al final de los Tiempos, materializada en el Pantocrátor y el Tetramorfos.

Más abundantes son las escenas vinculadas a la Pasión que observamos en Villa del Prado, aunque su ejecución fue bastante más dilatada en el tiempo. Así, a la derecha del retablo, resta un fragmento de lo que parece un Cristo resucitado, seguramente realizado durante una primera fase decorativa, es decir hacia finales del siglo XV o el primer tercio del siglo $\mathrm{XVI}^{39}$. De dicha resurrección lo único que permanece es la cabeza de Cristo, nimbado, sosteniendo la banderola que indica su triunfo sobre la muerte.

35 La presencia de elementos propios de la devotio moderna estaría acorde con la cronología que se ha dado a la primera fase pictórica de Villa del Prado: fines del XV-primer tercio del XVI.

36 El gesto de las manos juntas sustituye desde el siglo XII al de las manos alzadas hacia el cielo, como forma de indicar súplica, respeto y sumisión a la voluntad divina, convirtiéndose desde entonces y hasta la actualidad en el más empleado por los cristianos. Un buen estudio sobre los gestos de oración, su génesis y cronología es el de J.C. SCHMITT, La raison des gestes dans l’Occident médiéval, París, 1990.

37 Se trata de un Cristo de tres clavos, situado sobre un fondo de estrellas y círculos esbozados en buril y sinopia.

38 La muerte de Cristo, uno de los temas cruciales del cristianismo, fue recogido tanto en los evangelios canónicos (Mateo 27, 33-56; Marcos 15, 22-41; Lucas 23, 33-49; Juan 19, 18-37) como en apócrifos (Actas de Pilato IX, 5 y X, 1-2), además de ser enriquecido por las prácticas litúrgicas de la Pasión. Jugó un papel decisivo en el arte medieval, ganando poco a poco en humanidad y alcanzando un gran dramatismo en los siglos de la Baja Edad Media.

39 La resurrección de Villa del Prado sería coetánea a una serie de escenas que hoy restan ocultas tras el retablo mayor: Adán y Eva, Santiago Matamoros, Pantócrator y Tetramofos. 
De una tercera fase decorativa que tuvo lugar en el siglo XVII ${ }^{40}$ son las vistas de una ciudad y los Arma Christi entre motivos florales ${ }^{41}$ que aparecen respectivamente en los muros y bóvedas de la Capilla del Cristo Crucificado, a los pies del templo. La ciudad que vemos podría ser la propia Jerusalén ya que sobre sus edificios se alza la cruz flanqueada por la luna y el sol. Así, a través de la evocación de la crucifixión, el fiel recupera la esperanza de su entrada en la Jerusalén celeste, imagen y espejo de la terrestre.

Además habría que mencionar que en Villa del Prado, en la parte alta de los muros y entre las bóvedas, aparecen una serie de cruces, de cronología desconocida, que tal vez marcasen las diferentes estaciones de un Vía Crucis, además de recordar la consagración del templo. Son cruces sumamente esquemáticas y lineales, trazadas con tintas rojas o negras dependiendo de los casos, que se reparten por la práctica totalidad del templo.

En cuanto a los apóstoles, hay varios ejemplos de ellos en los conjuntos estudiados, representados por parejas o agrupados en serie, ubicados casi siempre bajo el Pantocrátor. Son, en este caso, parte de la corte que acompaña a la divinidad en la Jerusalén celeste y al mismo tiempo aquéllos que se encargan de difundir el mensaje de Cristo en la tierra. Así, en Torremocha hallamos a San Pedro y San Pablo, cabezas y representantes de las dos iglesias (judíos y gentiles respectivamente), flanqueando la Crucifixión y bajo el Pantocrátor, así como al resto del colegio apostólico en la bóveda del tramo recto. Con anterioridad al s. XV, en Valdilecha, ya habían aparecido en el friso bajo el Pantocrátor, enmarcados por arcos, ocho apóstoles, prácticamente perdidos pero reconocibles por sus cartelas ${ }^{42}$.

En otras ocasiones los apóstoles aparecen como figuras aisladas, al modo de otros santos a los que se dedica el templo o bajo los cuales se busca protección. Es el caso de Santiago matamoros en Villa del Prado, o San Bartolomé y San Juan en Carmarma.

Las representaciones hagiográficas de los conjuntos murales estudiados evidencian los cambios devocionales de fines de la Edad Media y están plenamente inser-

40 En los nervios de las bóvedas de esta capilla aparece una inscripción que marca la fecha de realización: 1647. Dice así "ANO PINTOSE, A ONRA, Y GLORIA, DE DIOS NUESTRO S. Y DE SU BENDITA MADRE POR SIEMPRE JAMÁS 1647”' (J. AGUILERA et alii, op. cit., 2003, p. 98).

41 Los Arma Christi que aquí se recogen son la escalera, los dados, el gallo sobre la columna, el cuchillo con el que Pedro corta la oreja a Malco, el cáliz, la Santa Faz impresa sobre el velo de Verónica, el flagelo, la lanza, la esponja y los tres clavos. Las Arma Christi se habían popularizado en la Baja Edad Media gracias a la llegada de reliquias de la Pasión a Occidente a raíz del saqueo de Constantinopla de 1204, pero también gracias a los escritos místicos de Ludolfo de Sajonia (Vita Christi) y Brígida de Suecia (Revelaciones), y a la difusión de iconografías como la Misa de San Gregorio que situaba la aparición del crucificado sobre el altar rodeado de estos instrumentos de sufrimiento. Así que mostrarían una pervivencia de programas bajomedievales aún a mediados del siglo XVII. Para más detalle, puede leerse el estudio de P.S. DEL POZO COLL, "El ciclo de la Pasión y muerte de Cristo", E- excellence Liceus, 2006, pp. 25-27 (publicación digital).

42 I. BANGO et alii, op. cit., 1981, pp. 19-20; y A. DE LA MORENA BARTOLOMÉ, op. cit., 1994a, pp. 635-636. 
tas en la religiosidad y dramatismo bajomedieval. Además los santos son, junto a la Virgen, los intercesores por excelencia, que desempeñan una importante función de puente entre los hombres y la divinidad.

Uno de los que encontramos con mayor insistencia en Santiago matamoros ${ }^{43}$, que además de santo es apóstol. La iconografía de Santiago como miles christi que se enfrenta al infiel aparece en Villa del Prado, Griñón y seguramente también en Villamantilla ${ }^{44}$. En los tres casos nos hallamos ante lugares de repoblación, si bien es cierto que ésta se había producido varios siglos antes que los programas iconográficos estudiados $^{45}$.

Además de Santiago, encontramos un amplio elenco de santos, que responden a distintas motivaciones (devociones privadas y locales, comparación con la vida de Cristo, miedo ante epidemias cíclicas ${ }^{46}$, etc.). No siempre resultan reconocibles, ya que unas veces han perdido su símbolo parlante y otras la escena de la que forman parte se halla en un estado de conservación muy parcial. De los que es posible reconocer, habría que citar en Torremocha a Santa Lucía (en el ábside, con los ojos sobre una bandeja) y Santa Águeda (en el registro inferior del muro recto del presbiterio, con los pechos cortados sobre un plato). En Camarma, sobre los muros del presbiterio, se distinguen cuatro santos realizados hacia el siglo XV: San Sebastián (acosado por las flechas) ${ }^{47}$, San Eustaquio (contemplando el ciervo sobre cuya cornamenta aparece Cristo crucificado) ${ }^{48}$, San Bartolomé (con un macho cabrío

43 La primera representación de Santiago venciendo al infiel en la Batalla de Clavijo sería la del crucero sur de la catedral de Santiago (s. XIII), triunfando después en la Baja Edad Media y en la Edad Moderna, tanto en España como en Hispanoamérica. Para más detalle puede verse L. RODRÍGUEZ PEINADO, "Santos Caballeros", Proyecto de Innovación y Mejora de la Calidad Docente $n^{\circ}$ 87. Base de datos digital de iconografía medieval, UCM, 2009-2010, disponible en http://www.ucm.es/centros/cont/descargas/documento18747.pdf, último acceso 10 julio 2010.

44 En Villa del Prado, Santiago se sitúa en el cascarón del ábside, montando un caballo blanco. Tras él aparece un paisaje con caballeros de menor tamaño y delante de él un musulmán huyendo. En Griñón, Santiago está ubicado en el tramo recto que precede al ábside, a la izquierda, bajo la imagen de la Virgen del manto. Va armado y a caballo, cubierto con sombrero de ala ancha con la venera de los peregrinos a Compostela. En Villamantilla, hay una figura de difícil identificación situada en el vértice superior del retablo pintado. De ella se distingue que porta cruz y que se yergue junto a un caballo, por lo que podría tratarse de Santiago Matamoros.

45 Véase el apartado "Los soportes arquitectónicos de los murales madrileños del siglo XV" de este mismo artículo.

46 Es el caso del San Sebastián de Camarma y su relación con las epidemias de peste, que fueron especialmente virulentas en la Europa de los siglos XIV y XV.

47 San Sebastián, santo de origen francés de los siglos III-IV, aparece en el muro recto del presbiterio, en el lado norte. Desnudo y en el centro de la composición es acosado por las flechas de tres ballesteros, mientras los donantes, hombre y mujer con toca, se arrodillan a sus pies. En lo alto de la imagen la dextera dei rodeada de nimbo crucífero bendice al santo, siendo éste un elemento iconográfico arcaizante que entroncaría con los conjuntos románicos.

48 Sobre el vano sur del ábside aparecen unas figuras de pequeño tamaño que se han identificado con la historia de San Eustaquio. De la biografía de este santo, que habría sido general del ejércitos en la época de Trajano (s. II), nos interesa el momento de su conversión, que es el representado en Camarma de Esteruelas [Véase J.M. MACÍAS (trad.), Santiago de la Vorágine. La leyenda dorada, Madrid, 2001, vol. II, p. 88]. 
encadenado y sujeto a una de sus manos) $)^{49}$ y San Juan Bautista (seguramente con el cordero $)^{50}$. En esta misma iglesia, pero a la entrada del presbiterio y datados más tardíamente, en el siglo XVI-XVII, hallamos a San Juan Evangelista y San Antón. En el ábside de Villamantilla también aparecen un San Antón (sosteniendo un cayado y vestido con hábito religioso de tono grisáceo, destacándose la tau sobre su pecho) y un posible San Juan Evangelista ${ }^{51}$. Finalmente, en Colmenar Viejo, oculto bajo el retablo del altar mayor desde 1570, se hallaría una Misa de San Gregorio, realizada a inicios del siglo $\mathrm{XVI}^{52}$. Fue esta una escena de simbolismo funerario de gran éxito a finales de la Edad Media, ya que potenciaba el dramatismo de este período, favorecía la meditación sobre el dolor y la muerte de Cristo, e insistía en la polémica cuestión de la transubstanciación.

Sin embargo la escena admite otras interpretaciones ya que junto al caballo, delante de su lomo, el pintor ha silueteado una lanza que parece atravesar a este animal. Por ello se apunta como hipótesis alternativa que se trate de la imagen de San Huberto o San Gil, ya que ambos tienen como símbolo un ciervo, además de una enorme devoción en la Edad Media.

49 La figura identificada como San Bartolomé se halla en el extremo norte del paramento del ábside, en el lado opuesto a la posible escena del Bautista. Lo que ha llegado hasta nosotros es una figura masculina, de pie, desnuda casi en su totalidad, nimbada, con largos cabellos y espesa barba, que sostiene sobre sus hombros dos piernas y dos brazos. De la mano del santo pende una cadena que termina en un macho cabrío de color negro y posición erguida. Según Abad y Cuadrado, las manos y las piernas sobre el santo remitirían a la piel que le arrancaron en su martirio, ya que fue desollado vivo por orden del rey armenio Astiajes [C. ABAD y M. CUADRADO, "Unas pinturas bajomedievales inéditas en la iglesia parroquial de Camarma de Esteruelas (Madrid)", Archivo Español de Arte, 242 (1998), pp. 160-163]. Por otra parte, el macho cabrío encadenado aludiría al enfrentamiento del santo con el demonio del ídolo Astaroth, según las noticias recogidas por Santiago de la Vorágine (véase J.M. MACÍAS, op. cit., vol. II, 2001, pp. 524-525). Precisamente el detalle del demonio encadenado es uno de los detalles iconográficos que se asocia a San Bartolomé en la pintura española, no encontrándolo en otros lugares. De estar efectivamente ante una imagen de San Bartolomé, deberíamos prestar también atención a la mano izquierda del santo, que aunque hoy perdida por el deterioro de la capa pictórica, podría haber sostenido con ella el cuchillo, su símbolo más reconocible. Por otra parte, antes de ser restauradas las pinturas en la campaña de 1986-1991, aparecía junto a San Bartolomé otra figura humana, con tocado sobre su cabeza, que podría aludir al rey armenio Astiajes, aquel que ordenó su martirio.

${ }^{50}$ Casi totalmente perdida, en el extremo sur del paramento del ábside, justo a continuación del posible San Eustaquio, aunque en un registro inferior y de mayor tamaño, parecen adivinarse los restos de la historia del Bautista. San Juan, ataviado seguramente con una piel de camello (apenas visible en la parte inferior), portaría en sus manos el símbolo habitual, un cordero (véase M.J. ARNÁIZ et alii, op. cit., 1994, p. 57). Sin embargo, el estado de conservación enormemente deficiente en esta parte del muro hace imposible aseverar esta identificación. No deberíamos descartar otras hipótesis, como la que apunta Mayoral Moraga, que ve en los fragmentos de esta pintura los restos de una escena más arcaizante, la de Abel ofreciendo un cordero a Dios. Según éste, se habrían conservado los restos de los brazos de Abel ofreciendo el cordero y parte de una mano que podría ser la dextera dei recibiendo la ofrenda y bendiciendo. [M. MAYORAL MORAGA, op. cit., 1995].

51 Podríamos estar ante la figura de San Juan, el discípulo bienamado, ya que se nos muestra imberbe y de cabellera rubia, del mismo modo que suele representarse cuando se apoya en el regazo de Cristo durante la Última Cena para preguntarle cuál de los apóstoles le traicionará (Juan 13, 23-26). Porta la palma del martirio y un objeto muy desdibujado en su mano izquierda, que de ser San Juan habría de ser la copa del envenenamiento.

52 La descripción de estas pinturas puede leerse en A. DE LA MORENA BARTOLOMÉ, op. cit., 1994b, pp. 117-118. En el mencionado artículo se incluye una fotografía en blanco y negro (p. 119) y un esquema (p. 121) de las pinturas. 
En relación con las figuras de los santos, aunque con una presencia mucho más limitada en los conjuntos analizados, no habría que dejar de mencionar la imagen de la Virgen que aparece en Griñón y Navalafuente ${ }^{53}$, y que entroncaría con restos pictóricos anteriores al XV como los hallados en la cripta de la Almudena ${ }^{54}$. La Virgen desarrolló una importante labor intercesora y protectora equiparable a la de los santos en la Baja Edad Media. El ejemplo que más insiste en esta función de mediación es el de Griñón. Aquí hallamos a la Virgen de la Misericordia que despliega su manto para proteger con él a la humanidad, más concretamente a una serie de pequeñas figuras, situadas a su izquierda y en perspectiva jerárquica respecto a ella. Sus brazos estarían flexionados hacia arriba, bien en gesto de súplica, bien para sostener su manto.

Antes de concluir este apartado restaría mencionar los dragones de las nervaduras de Villa del Prado, que son absolutamente excepcionales en el conjunto de las iglesias madrileñas analizadas. No obstante se trata de un tema recurrente y que encontramos en otras muchas nervaduras de capillas parroquiales, conventuales y catedralicias de la Península Ibérica, datadas desde fines del s. XIV (Capilla de San Blas de la Catedral de Toledo) y hasta los inicios del s. XVI, como en el caso que nos ocupa, y asociadas en alguna que otra ocasión al apóstol Santiago ${ }^{55}$. El dragón puede tener un primer significado como alusión al diablo y al mal que hay que vencer y que finalmente es derrotado y glorifica a Dios (siguiendo textos tales como Isaías 43,20 y Apocalipsis 12,7). Un segundo significado estaría ligado a Santiago, ya que tras su muerte:

“[...] fue conducido por una tripulación de ángeles y llevado en naves mágicas, atravesando los dominios de las fieras y dragones salvajes que fueron amansándose al paso de la procesión fúnebre, hasta su llegada a Iria Flavia en la actual Coruña [...]"'56.

Además no hay que olvidar la importante función del dragón en el campo de la heráldica. Ninguna hipótesis ha de ser descartada; estos dragones se incorporarían al programa iconográfico actuando como elementos profilácticos que anulan el mal, reforzando la figura de Santiago, o como parte de la heráldica.

\section{Conclusión}

Podríamos decir que en el siglo XV se apocopan los estilos medievales en la pintura mural de la actual Comunidad madrileña. La razón es que desde la perspec-

${ }_{53}$ En Navalafuente la posible imagen de la Virgen, muy deteriorada, está flanqueada por dos donantes, a un lado el caballero y al otro la dama, arrodillada y con tocado alto. No obstante, podría tratarse de cualquier otra santa/o y no de la Virgen, ya que lo que hoy subsisten son unas leves trazas.

${ }^{54}$ En la cripta de la Almudena la que hayamos es la conocida como la Virgen de la flor de lis, que con una mano sostiene a su hijo y con otra la flor [A. DE LA MORENA BARTOLOMÉ, "La antigua iglesia de Nuestra Señora de la Almudena", La Almudena y Madrid, Madrid, 1993].

${ }_{55}$ J. AGUILERA et alii, op. cit., 2003, p. 81.

${ }^{56}$ Ibidem, p. 81. 
tiva histórica, el actual territorio resulta artificial. Pero su geoestratégica ubicación, condicionada por su centralidad geográfica entre las dos mesetas y las cuencas de sus ríos, la condicionan como lugar de "aluvión" cultural. De una primera dependencia toledana en la época tardorrománica (Valdilecha), que marca un tema iconográfico que va a perdurar hasta finales del XV, se pasa a la influencia abulense a finales del siglo XIV con la pervivencia del estilo lineal (Camarma), hasta que a mediados del XV aparece la aragonesa a través de Guadalajara con una muestra del nuevo estilo internacional (Torremocha), para a finales del siglo acusar de nuevo la influencia toledana (la natural por gobernabilidad religiosa y política), pero ahora imbuida de los avances técnicos del primer Renacimiento Italiano (Villa del Prado) y en la que el elemento hispanoflamenco es un sustrato cultural más o menos secundario (Colmenar Viejo, Valdelaguna y Griñón). Madrid en la Edad Media no era tal, sino segoviana hasta la sierra, manchega en el llano y fronteriza por el este. Como consecuencia era diversa y periférica en su arte pictórico mural, como también lo fue su arquitectura, primitiva o nueva, mudéjar o gótica, que le sirvió de soporte.

\begin{tabular}{|l|l|l|l|}
\hline TEMPLO & CRONOLOGÍA & (ESTILO)- Filiación & TÉCNICA \\
\hline Precedente & h. 1250-1275 & (TARDORROMÁNICO) & $\begin{array}{l}\text { FRESCO MIXTO CAL } \\
\text { Y ARENA }\end{array}$ \\
\hline VALDILECHA & Toledana \\
\hline \multicolumn{5}{|c|}{ A Abulense } \\
\hline Ausencia de murales del siglo XIV (ITALOGÓTICO)
\end{tabular}

